Gyu-Ho Shin and Sun Hee Park*

\title{
Isomorphism and language-specific devices in comprehension of Korean suffixal passive construction by Mandarin-speaking learners of Korean
}

\author{
https://doi.org/10.1515/applirev-2020-0036 \\ Received May 12, 2020; accepted March 9, 2021; \\ published online March 26, 2021
}

\begin{abstract}
Across languages, a passive construction is known to manifest a misalignment between the typical order of event composition (agent-before-theme) and the actual order of arguments in the constructions (theme-before-agent), dubbed non-isomorphic mapping. This study investigates comprehension of a suffixal passive construction in Korean by Mandarin-speaking learners of Korean, focusing on isomorphism and language-specific devices in the passive. We measured learners' judgment of the acceptability of canonical and scrambled suffixal passives as well as their reaction times (relative to a canonical active transitive). Our analysis generated three major findings. First, learners uniformly preferred the canonical passive to the scrambled passive. Second, as proficiency increased, the judgment gap between the canonical active transitive and the canonical suffixal passive narrowed, but the gap between the canonical active transitive and the scrambled suffixal passive did not. Third, learners (and even native speakers) spent more time in judging the acceptability of the canonical suffixal passive than they did in the other two construction types. Implications of these findings are discussed with respect to the mapping nature involving a passive voice, indicated by language-specific devices (i.e., case-marking and verbal morphology dedicated to Korean passives), in L2 acquisition.
\end{abstract}

Keywords: case-marking; isomorphism; Korean; passive construction; verbal morphology

\footnotetext{
*Corresponding author: Sun Hee Park, Department of Korean Studies, Ewha Womans University, Seoul, Korea, E-mail: sunheepark@ewha.ac.kr

Gyu-Ho Shin, Department of Asian Studies, Palacky University Olomouc, Olomouc, Czech Republic, E-mail: gyuho.shin@upol.cz
} 


\section{Introduction}

Previous studies have documented the apparent delay in the acquisition of a passive construction across languages (e.g., Abbot-Smith et al. 2017; de Villiers and de Villiers 1973; Huang et al. 2013; Nguyen and Snyder 2017; Sano et al. 2001). A similar challenge in the acquisition of the passive has also been observed in a second language (L2) learning context (e.g., Balcom 1997; Hinkel 2004; Izumi and Lakshmanan 1998; Ju 2000; Shin and Jung 2021). Researchers have proposed various explanations for this delay. One viewpoint addresses this challenge by way of structural considerations such as the difficulty involving the movement of arguments in the passive (e.g., Borer and Wexler 1987) and the lack of thematic role transmission for the arguments in the passive (e.g., Fox and Grodzinsky 1998). An alternative viewpoint highlights an interplay of exposure and processing issuesnamely, the extremely low frequency of a passive voice in input (e.g., Brooks and Tomasello 1999), and the limitations of a linguistic parser for the passive (e.g., Abbot-Smith et al. 2017; Huang et al. 2013), amongst others.

In this study, we employ this alternative view, with a special focus on the processing difficulty involving the passive construction. One promising source for this challenge comes from the unusual mapping relation between an event representation and a syntactic representation involving a passive voice, dubbed the isomorphic mapping hypothesis (Dik 1997; O'Grady and Lee 2005). According to this hypothesis, the passive construction is non-isomorphic by nature insofar as the canonical order of arguments in this construction (theme-before-agent) does not follow the typical order of event composition (agent-before-theme) (cf. Langacker 1991; Talmy 1988) as schematised in the English example (1).

(1)

\begin{tabular}{|c|c|c|}
\hline $\mathrm{X} /$ agent acts on $\mathrm{Y} /$ theme & event & $\mathrm{X}$ /agent acts on $\mathrm{Y} /$ theme \\
\hline John chased Mary. & sentence & Mary was chased by John \\
\hline omorphic & mapping & non-isomorphic \\
\hline
\end{tabular}

Indeed, non-isomorphic mapping inherent to the passive construction is closely related to the process where the agent is downgraded to an oblique position, which reflects the basic function of a passive voice-defocusing the agent (Haspelmath 1990; Shibatani 1985; Siewierska 2013). This process results in the agent losing its status as the subject and instead the theme occupying the subject position. The operation involved in non-isomorphic mapping also goes against a predisposition that links the first argument to the agent, dubbed the agent-first preference (e.g., Abbot-smith et al. 2017; Slobin and Bever 1982), which is 
typologically common (e.g., Dryer 2013) and believed as an intrinsic bias that speakers employ in comprehension (e.g., Fisher 2002; Jackendoff and Wittenberg 2014) and production (e.g., Goldin-Meadow et al. 2008). It is thus expected that the atypical association between the two representations increases processing costs, resulting in worse performance in such cases than in cases involving isomorphic mapping. In this regard, the learners' task is to perceive the mismatch between the two representations of the passive construction and to calculate the precise thematic roles of each argument.

The isomorphic mapping hypothesis was proposed to explain agrammatic comprehension deficits (O’Grady and Lee 2005). Normal children learning their native languages have also been shown to experience similar challenges in revising their initial mapping between thematic roles and grammatical relations when comprehending the passive (e.g., Abbot-smith et al. 2017; Huang et al. 2013; Shin 2020), supporting the argument of this hypothesis. In addition, several L2 studies have reported the benefit of isomorphic mapping over non-isomorphic mapping in comprehension of active voice constructions such as locatives and instrumental (e.g., Ito 2007; O'Grady et al. 2005). Less clear is how the mapping relation between event and syntactic representations addresses L2 learners' acquisition of the passive construction, which has not been actively investigated (cf. MacWhinney 1997). Also unanswered is how (non-)isomorphic mapping interacts with language-specific devices engaging in the passive for L2 comprehension.

With these in mind, the present study investigates comprehension of a Korean suffixal passive construction ${ }^{1}$ by Mandarin-speaking learners of Korean, focusing on

1 There are two more types of passives in Korean. One is a lexical passive (a), which includes no passive marker on a verb, but the meaning of the verb (e.g., mac- 'be hit') is one of affectedness. Moreover, case-marking is the same as in the suffixal passive, ensuring its status as a genuine passive.

(a)

$\begin{array}{lll}\text { Lexical passive } & & \\ \text { Chelswu-ka } & \text { Minho-eykey } & \text { mac-acc-ta. } \\ \text { Chelswu-NOM } & \text { Minho-DAT } & \text { get.hit-PST-SE } \\ \text { 'Chelswu was/got hit by Minho.' } & \end{array}$

The other is a periphrastic passive (b) in which the theme is expressed by the nominative case marker but the agent is expressed mostly by -ey uyhay, rather than by the dative markers. This type of passive has a combination of a suffix $-e / a$ and an inchoative verb ci- 'to become' after the verb stem.

(b) Periphrastic passive

$\begin{array}{lll}\text { chayk-i } & \text { Chelswu-ey uyhay } & \text { ccic-eci-ess-ta. } \\ \text { book-NOM } & \text { Chelswu-by } & \text { tear-become.PSV-PST-SE }\end{array}$

'The book was torn by Chelswu.' 
the interplay between the mapping relation of the two representations involving the passive and language-specific devices for the passive. Korean is a Subject-ObjectVerb language with overt case-marking by dedicated markers. These structural cues allow scrambling of pre-verbal arguments as long as that reordering preserves the original intention with no ambiguity. Composing the suffixal passive in Korean requires the use of special devices such as case-marking and verbal morphology dedicated to this construction type, indicating the mapping nature of the two representations. Mandarin has a marker to indicate the passive voice, which is functionally similar to (and yet structurally different from) passive morphology in Korean, and lacks case-marking that operates only in conjunction with passive morphology. These characteristics present a unique testbed for examining a language-specific mechanism for L2 development in relation to the isomorphic mapping hypothesis.

\section{Background}

\subsection{Acquisition of suffixal passives by second language learners of Korean}

A suffixal passive is formed by attaching one of the passive markers - $i$-, -hi-, -li-, or $-k i$ - to a verb stem with a nominative-marked subject indicating a theme and a dative-marked oblique indicating an agent. ${ }^{2}$ A canonical suffixal passive (2a) follows the theme-agent ordering, and thus non-isomorphic. The canonical pattern can be scrambled ( $2 \mathrm{~b}$ ); this yields the agent-theme ordering, and thus isomorphic in its mapping nature.

All three types of passive constructions are rare in input, but of the three passive types, lexical and periphrastic passives are extremely rare (Shin 2020). The range of the lexical passive is limited to several verbs such as mac- 'to be hit', tangha- 'to undergo', pat- 'to receive (an action), and to suffer', and toy- 'to become' only when it is combined with verbal nouns (e.g., sayong-toy-ta 'to be used') (Sohn 1999). Moreover, the subject of the periphrastic passive is mostly inanimate, which does not correspond to the pattern that we investigated where the agent and the theme were reversible within a sentence. Therefore, we focus on the suffixal passive with two animate nouns present in a sentence hereafter.

2 The dative marker -hanthey is used more frequently than -eykey in colloquial and casual contexts. - ey is also used to indicate the agent in a passive construction, but only for an inanimate agent (Sohn 1999). We limit the scope of discussion to the passive with an animate agent. 
(2a) Canonical suffixal passive

totwuk-i kyengchal-hanthey cap-hi-ess-ta.

thief-NOM police-DAT catch-PSV-PST-SE ${ }^{3}$

'The thief was caught by the police.'

(2b) Scrambled suffixal passive

kyengchal-hanthey totwuk-i cap-hi-ess-ta.

police-DAT thief-NOM catch-PSV-PST-SE

'The thief was caught by the police.'

L2-Korean learners encounter two major challenges when acquiring the suffixal passive in Korean. One comes from case-marking. Information about case-marking in the passive is crucial for interpreting the thematic roles of individual arguments, but it is inconsistent with the information in an active voice counterpart (which is dominantly attested in most descriptions of transitive events). For example, whereas the nominative case marker usually indicates the agent in the active transitive (3), the same marker indicates the theme in the suffixal passive (4). Instead, the agent in the passive is indicated by the dative marker, which is often used to indicate a recipient in a ditransitive construction (Choo and Kwak 2008; Sohn 1999).

(3) Nominative case marker indicating the agent in the active transitive

$\begin{array}{lll}\text { kyengchal-i } & \text { totwuk-ul } & \text { cap-ass-ta. } \\ \text { police-NOM } & \text { thief-ACC } & \text { catch-PST-SE }\end{array}$

'The police caught the thief.'

(4) Nominative case marker indicating the theme \& dative marker indicating the agent in the suffixal passive (example: canonical)

$\begin{array}{lll}\text { totwuk-i } & \text { kyengchal-hanthey } & \text { cap-hi-ess-ta. } \\ \text { thief-NOM } & \text { police-DAT } & \text { catch-PSV-PST-SE }\end{array}$

'The thief was caught by the police.'

Therefore, L2-Korean learners must figure out the following facts regarding the suffixal passive: an argument indicated by the nominative case marker is not the agent but the theme, and there is a new association (i.e., the pairing of the dative marker and the agent role) only for the passive.

The other challenge that L2 learners must overcome in acquiring the suffixal passive is verbal morphology. A verb in the suffixal passive is marked with one of the

3 Abbreviation: ACC = accusative case maker; DAT $=$ dative marker; $\mathrm{NOM}=$ nominative case marker; $\mathrm{PERF}=$ perfective marker; $\mathrm{PST}$ = past tense marker; $\mathrm{PSV}=$ passive suffix; $\mathrm{SE}=$ sentence ender. 
four suffixes, and this morphology indicates that a sentence is in a passive voice (and the passive is non-isomorphic by nature, as found in passive constructions in other languages; cf. Siewierska 2013). In this respect, passive morphology serves as a key disambiguation point-it is only this morphology that tells a comprehender that the nominative-marked argument is not the agent of the event (and the dative-marked argument becomes the agent instead). Sensitivity to passive morphology is thus crucial for the successful comprehension of the Korean suffixal passive. However, the four passive suffixes are morphologically irregular due to their unsystematic distribution (e.g., Yeon 2015), they are unproductive since they apply only to a limited set of verbs (e.g., Lee and Lee 2008; Sohn 1999), and they are used for a morphological causative construction as well (e.g., Song 2015). Moreover, passive morphology in Korean allows for revision, not guidance, of the initial interpretation due to verb-finality (cf. Pozzan and Trueswell 2015), so learners must adjust their first (and tentative) understanding of the sentence immediately after encountering a passive morphology, also considering canonicity of the sentence. Such passivemorphology-related intricacies create extra burdens for L2 learners in acquiring the suffixal passive in Korean.

To date, few studies have examined the acquisition of the Korean passive construction by L2-Korean learners. One systematic investigation was made by Jeong (2014): using a picture-sentence verification task, he investigated Mandarinspeaking learners' processing of truncated suffixal passive patterns as in $(5 a-b)$.

(5a) Nominative-only suffixal passive

enni-ka cap-hi-eyo.

sister-NOM catch-PSV-SE

'The sister is caught (by the brother).'

(5b) Dative-only suffixal passive

oppa-eykey cap-hi-eyo.

brother-DAT catch-PSV-SE

'(The sister) is caught by the brother.'

Results showed that learners' knowledge about these passive patterns improved notably as their language proficiency increased, and that they processed the dative-only passive pattern significantly faster than the nominative-only passive pattern. Moreover, the study showed that learners demonstrated higher rates of accuracy in the dative-only passive pattern than in the nominative-only active pattern. These findings imply that L2 learners generally benefit more from the agent-first preference than from case-marking and passive morphology when comprehending the suffixal passive. 
Despite the significance of these findings, the truncated passive patterns involve only one overt argument, which makes it difficult to precisely measure how the mapping relation of the two representations, in conjunction with casemarking and verbal morphology, affects L2 learners' comprehension of the passive. These limitations create the need to explore how L2-Korean learners comprehend a full suffixal passive construction in consideration of the aforementioned novel form-function pairings in case-marking and unusual passive morphology on a verb.

\subsection{A comparative look at passives in Mandarin and Korean}

As we investigate the acquisition of the Korean suffixal passive construction by Mandarin-speaking learners of Korean, a brief examination of a passive construction in Mandarin is warranted. The basic word order in Mandarin is Subject-Verb-Object (Sun and Givon 1985); when it comes to the passive, the theme moves to the front of the sentence and the agent is placed between the theme and the verb (Li and Thompson 1981). ${ }^{4}$ This yields a theme-agent ordering (7), which conforms to non-isomorphic mapping (just like the Korean canonical suffixal passive). However, the Mandarin passive does not allow scrambling of arguments and thus differs from the Korean scrambled suffixal passive in its thematic role ordering (i.e., agent-before-theme).

$$
\begin{aligned}
& \text { Zhangsan bei Lisi da-le. } \\
& \text { Zhangsan PSV Lisi hit-PERF } \\
& \text { 'Zhangsan was hit by Lisi.' } \quad \text { (Example from Liu 2016) }
\end{aligned}
$$

Passive constructions across the two languages differ in terms of verbal morphology. Mandarin has a special marker bei, which is exclusively used-between the theme and the agent-to signal a passive voice in Mandarin (Huang et al. 2013; Li and Thompson 1981; McEnery et al. 2003; see also Liu 2016 for the comprehensive review on the status of bei). This marker is functionally similar to passive morphology in Korean as it indicates that the sentence is in a passive voice, but it has a regular, fixed form and is not inserted into a verb. This is in contrast with how passive morphology in Korean works (manifesting morphological intricacies

\footnotetext{
4 Corpus findings revealed that the passive appears far less frequently than active voice constructions in Mandarin (e.g., Xiao et al. 2006), which is consistent with the rare use of a passive voice in Korean (e.g., Shin 2020).
} 
and applying to the revision of initial interpretation; Section 2.1). This crosslinguistic difference likely affects Mandarin-speaking learners' comprehension of the Korean suffixal passive, rendering their efforts to understand the passive in Korean less successful (and more costly). Indeed, previous studies have reported L2 learners' unsuccessful acquisition of inflectional morphemes in target languages when such morphemes do not exist or behave in different ways in their native languages (e.g., Jiang et al. 2011; Lardiere 2009; Slabakova 2014).

Case-marking also serves as a crucial feature for comparing the passive constructions in the two languages. Whereas Mandarin has no case-marking for the passive, Korean has two markers for the passive-the nominative case marker indicating the theme; the dative marker indicating the agent. Moreover, the formfunction pairings of each marker involving the Korean passive are infrequent and thus atypical: the nominative case marker is used normally for the agent, and the dative marker often indicates the recipient (Section 2.1). These characteristics would influence Mandarin-speaking learners' comprehension of the Korean passive construction considerably, producing the same kind of difficulty that passive morphology invites.

More importantly, we expect to find an interplay between the mapping relation of the passive construction (which concerns the entire sentential frame) and the language-specific devices used only for the passive (which concerns local formfunction pairings of case-marking confirmed by verbal morphology). Nonisomorphic mapping is the default mapping relation in the Mandarin passive (and it also fits with the nature of a passive construction across languages in general). Therefore, when Mandarin-speaking learners of Korean comprehend the Korean canonical suffixal passive, they may benefit from the same kind of non-isomorphic mapping found in the passive in their native language. In contrast, the Korean scrambled suffixal passive may bring difficulty in comprehension, due to conflicting information from case-marking (with the first argument as the agent indicated by the dative marker and thus isomorphic) and verbal morphology (signalling that the sentence is in a passive voice and thus non-isomorphic by nature).

With these considerations in mind, the present study sets out to examine how Mandarin-speaking learners of Korean comprehend the Korean passive construction by canonicity and by proficiency. We specifically inquire about how their comprehension relates to the mapping nature of the two representations, together with language-specific devices in the passive. We conducted an acceptability judgment task with a reaction time measurement targeting three learner proficiency groups. 


\section{Methods}

\subsection{Participants}

Sixty-eight adult Mandarin-speaking learners of Korean (mean age = 24.2, SD = 3.10), who were either exchange students or postgraduate students attending one university in Korea, participated in this experiment. They were divided into three proficiency groups: high $(n=20)$, intermediate $(n=26)$, and low $(n=22)$. Their language proficiency was measured separately by using a set of questionnaires extracted from the Test of Proficiency in Korean. This set consisted of 20 multiplechoice items which measure various types of grammatical knowledge for non-native speakers of Korean, and its reliability/validity was proven (e.g., Jeong 2017; Hee and Hyunwoo 2017). Participants' responses were coded as 0 (wrong) and 1 (correct). An ANOVA of the mean scores of the three proficiency groups proved significance, $F(2$, $65)=347.844, p<0.001$, and pairwise comparisons also showed significant differences across the groups, confirming that the three groups had distinct proficiency levels in Korean (see Appendix A for the full information about the experimental group). We also recruited 30 adult native speakers of Korean (mean age $=32.5$, $\mathrm{SD}=2.87$ ) as a control group. They were mostly postgraduate students attending the same university. All the participants were paid 5,000 Korean Won (equivalent to approximately \$5) as compensation for their participation.

\subsection{Stimuli}

Sixteen suffixal passive sentences (one half for the canonical passive; the other half for the scrambled passive) and eight canonical active transitive sentences (as a baseline $)^{5}$ were created by using common human names as the agents and the themes altogether. We controlled for the animacy of each argument to make reversible sentences (see Appendix B for a complete list of the test sentences). Verbs were also something that is commonly used in Korean. ${ }^{6}$ There was no overlap in the

5 The canonical active transitive is the most representative and basic constructional pattern relating to the type of event that the passive intends to express (i.e., a transitive event), thus serving as a baseline condition. We did not include the scrambled active transitive in the experiment considering the scope of investigation in this study (i.e., the passive construction) and frequency effects that should be controlled for the interpretation of results. Additional experiment including the scrambled active transitive may reveal interaction between canonicity and voice with respect to isomorphism.

6 We acknowledge the possibility that some names and verbs may occur more frequently or be more familiar to learners than others, which might have affected the participants' performance. We 
names and the verbs across the test sentences. We normed these sentences prior to the actual experiment by asking another 10 native speakers of Korean whether or not the sentences were grammatical. ${ }^{7}$ They judged all the test sentences to be grammatical (mean rate of grammaticality $=0.988, \mathrm{SD}=0.11$ ). One rater rejected two active sentences (siwu-NOM myengswu-ACC paint-PST-SE; sungha-NOM cengho-ACC pick-PST-SE), but the majority of the raters did not report any issue with these sentences, so we decided to use them for the experiment. In order to mask the intention of the experiment, on top of the test sentences, we added 48 fillers including ditransitives, locatives, and multiple subject/object constructions (some of which were scrambled) and 12 ungrammatical sentences.

\subsection{Procedure}

Using the test sentences and fillers, we conducted an online acceptability judgment task via Qualtrics, a web-based survey platform (cf. Enochson and Culbertson 2015). Participants were asked to rate the acceptability of the sentences on a 4-point Likert scale (1: very unacceptable; 4: very acceptable) and to do so as quickly as possible so that they would respond immediately upon encountering test sentences. All sentences were presented in random order and displayed on a computer screen individually (i.e., one by one). We collected participants' reaction times in judging each sentence to measure the processing cost during the acceptability judgment task. We measured the duration from the very outset of the presentation of a sentence as a whole to the participants' final decision regarding its acceptability (by clicking one of the scales). Once participants clicked the scale and moved to the next sentence, they were prohibited from re-examining previous sentences and revising their judgment. To ensure the stability of the test environment, the experiment was conducted in a designated location in the university under the supervision of research assistants.

\subsection{Analysis}

Data from the acceptability judgment task were fitted to linear regression models with Group (native speaker, high-proficiency, intermediate-proficiency, low-

\footnotetext{
believe that replication of these tests with the frequency of names and verbs controlled would likely confirm our current findings.

7 We conducted this norming task to reflect the intuitive understanding of linguistically naïve, ordinary speakers of Korean. See Dąbrowska (2010) for a discussion of the extent to which linguists' judgments deviate from the judgments of language users in general.
} 
proficiency) and Construction (active, canonical passive, scrambled passive) as independent variables and acceptability rating as a dependent variable. Instead of factoring all the construction types into a single analysis, we conducted pairwise comparisons (active vs. canonical passive; active vs. scrambled passive; canonical passive vs. scrambled passive) to ensure that the statistical analyses proceeded systematically by controlling for specific aspects of the constructions such as the mapping nature and language-specific devices. We originally attempted to fit the data to mixed-effects models, but the models failed to converge, irrespective of the random-effects structures. This prevented us from using mixed-effect modelling, which ultimately led us to employ linear regression as an alternative.

Data from the reaction time measurement were trimmed first by using a three-standard-deviation cut-off point (data loss: 9 out of 744 cases, 1.21\%), and the trimmed data were then log-transformed to satisfy the normal distribution requirement (Ratcliff 1993). The pre-processed data were fitted to linear mixedeffects models by using the lme 4 software package (Bates et al. 2015) with Group (native speaker, high-proficiency, intermediate-proficiency, low-proficiency) and Construction (active, canonical passive, scrambled passive) as fixed effects (deviation-coded and centred around the mean) and participant and sentence as random effects. We conducted pairwise comparisons due to the same reason as the analysis of the acceptability judgment data. The models included the maximal random effects structure with random intercepts and random slopes for all effects (Barr et al. 2013).

All the statistical modelling and hypothesis testing were performed in $R(R$ Core Team 2019).

\subsection{Prediction}

\subsubsection{General predictions regarding the passive construction}

First, the learner groups should rate the two passive patterns less acceptable than the canonical active transitive construction, reflecting the challenge in the acquisition of a passive voice attested across languages. Second, the judgment gap between the canonical active transitive and the two passive patterns should be smaller as proficiency increase. Third, considering reports on L2 learners' general difficulty in online processing (e.g., Clahsen and Felser 2006; Hopp 2014; McDonald 2006; Omaki and Schulz 2011), the learners should spend more time in rating the acceptability of the test sentences than the native speakers, independently of proficiency. 


\subsubsection{Predictions for pairwise comparisons by construction}

The canonical suffixal passive involves non-isomorphic mapping between the event and syntactic representations, together with atypical case-marking and verbal morphology. These characteristics should incur additional processing cost, causing learners to spend more time on this constructional pattern than on the canonical active transitive. This passive pattern shares the same kind of mapping relation that manifests in the Mandarin passive. If this overlap helps the learners to comprehend the Korean canonical suffixal passive, they should judge this pattern to be more acceptable than its scrambled counterpart.

On the contrary, the scrambled suffixal passive involves isomorphic mapping and yet the same case-marking and verbal morphology as its corresponding canonical pattern. Therefore, the increase in reaction times relative to the canonical active transitive should be smaller than the increase for canonical suffixal passive. Moreover, the learners should rate the scrambled suffixal passive as less acceptable than the other two construction types. This is because it has an unusual mapping relation as a passive voice (which cannot be found in the learners' native language), together with unusual case-marking and verbal morphology (which are also not assisted by their native language).

\section{Results}

Table 1 summarises the results from the acceptability judgment and reaction time measurement. ${ }^{8}$

\footnotetext{
8 A reviewer pointed out the possibility that, as the test sentences provided a contrast involving the nominative case marker (indicating an agent in actives vs. indicating a theme in passives) but no such contrast involving the dative marker (indicating an agent in passives only), participants might have created a bias that maps the dative marker onto the agent quickly as the experiment proceeded, resulting in faster reaction times for the scrambled suffixal passive than for the canonical suffixal passive. We are somewhat sceptical about this possibility because of (i) the fillers interspersed with the test items and (ii) the same kind of recalculation process involving casemarking (incurred by passive morphology) required for both passive patterns. Meanwhile, we are sympathetic with the reviewer's opinion that knowledge that is not intended to measure in an experiment (e.g., the dative marker for indicating an experiencer in a psych-verb construction) may serve as a confounding factor. Debates on this aspect is out of scope in this study in that the current experimental setting allows a comprehender to encounter one single sentence as a whole; we believe this to be addressed in a separate study (preferably employing a self-paced reading or an eye-tracking paradigm).
} 
Table 1: Result: Acceptability judgment and reaction time (raw data).

\begin{tabular}{llrr}
\hline Group & Construction & \multicolumn{2}{c}{ Mean (SD) } \\
\cline { 3 - 4 } & & $\begin{array}{r}\text { Acceptability judgment } \\
\text { (mean out of 4) }\end{array}$ & $\begin{array}{r}\text { Reaction time } \\
\text { (after 3SD cut-off) }\end{array}$ \\
\hline \multirow{2}{*}{ Native speaker } & Canonical active transitive & $3.46(0.92)$ & $4,299(313)$ \\
& Canonical suffixal passive & $3.61(0.65)$ & $5,190(300)$ \\
High & Scrambled suffixal passive & $3.43(0.70)$ & $4,347(242)$ \\
& Canonical active transitive & $3.56(0.87)$ & $6,453(319)$ \\
\multirow{4}{*}{ Intermediate } & $3.49(0.83)$ & $7,925(401)$ \\
& Canonical suffixal passive & $2.61(1.00)$ & $6,441(305)$ \\
& Scrambled suffixal passive & $3.71(0.61)$ & $7,129(324)$ \\
& Canonical active transitive & $3.29(0.87)$ & $8,531(410)$ \\
& Canonical suffixal passive & $2.52(0.99)$ & $7,573(379)$ \\
& Scrambled suffixal passive & $3.20(0.90)$ & $7,226(393)$ \\
& Canonical active transitive & $2.78(0.90)$ & $9,140(418)$ \\
& Canonical suffixal passive & $2.28(0.86)$ & $7,465(376)$ \\
\hline
\end{tabular}

Our analysis showed three notable tendencies regarding acceptability judgment. First, the learners' judgment of the two passive constructions improved as their proficiency increased. Second, the judgment gap between the canonical active transitive and the canonical suffixal passive narrowed as proficiency increased ( 0.42 for the low-proficiency group; 0.42 for the intermediate-proficiency group; 0.07 for the high-proficiency group). Third, all the learner groups (and even the native speakers) rated the scrambled suffixal passive as less acceptable than the canonical suffixal passive.

As for reaction times, the learners spent more time in rating the acceptability of each construction than the native speakers in general, and the amount of time that the learners spent decreased as proficiency increased. This indicates that L2 learners generally experience difficulties in online processing, which is attributable to the global deficits in L2 syntactic processing (e.g., the shallow structure hypothesis; Clahsen and Felser 2006), learners' improper use of linguistic resources due to processing limitations (e.g., Omaki and Schulz 2011), the nature of L2 processing vulnerable to the task environment (e.g., McDonald 2006), or individual differences in memory capacity (e.g., Hopp 2014). Pinpointing the precise cause of L2 learners' increased processing cost is not the focal point of this study, so we leave this issue for future studies. Interestingly, all participants spent more time in judging the acceptability of the canonical suffixal passive than they did in judging the acceptability of the other two constructions. 
Based on these results, we conducted statistical analyses (with the $Z$-transformed data for the acceptability judgment and the log-transformed data for reaction times) by grouping two construction types into pairs.

\subsection{Statistical comparison: canonical active transitive versus canonical suffixal passive}

Relative to the canonical active transitive, the canonical suffixal passive is nonisomorphic with the thematic roles indicated by unusual case-marking, together with passive morphology.

\subsubsection{Acceptability judgment}

In the global model, we found main effects of Group $(\beta=-0.154, S E=0.026$, $t=-5.801, p<0.001)$ and Construction $(\beta=-0.151, S E=0.060, t=-2.489, p=0.013)$, along with an interaction effect between these two factors $(\beta=-0.200, S E=0.053$, $t=-3.767, p<0.001)$. This indicates that the rate of acceptability differed by proficiency and by construction types, and more importantly, the size of the judgment gap across the two constructions narrowed as proficiency increased.

We also conducted by-construction and by-group comparisons. The by-construction analysis (Table 2) revealed significant differences in the intermediate- and low-proficiency groups' judgments between the canonical active transitive and the canonical suffixal passive. This points to the two groups' lower ratings for the passive than for the active transitive. The analysis also revealed differences in the acceptability judgment regarding the canonical suffixal passive across the learner groups (Table 3). There was no significant difference between either the native speaker group and the high-proficiency group or the high-proficiency group and the intermediate-proficiency group, but the ratings of the high- and the intermediate-proficiency groups differed significantly from those of the lowproficiency group.

Table 2: Linear regression: Comparison between the canonical active transitive and canonical suffixal passive constructions by group (acceptability judgment) (alpha level $=0.025$ ).

\begin{tabular}{lrrrr}
\hline Group & $\boldsymbol{\beta}$ & $\boldsymbol{S E}$ & $\boldsymbol{t}$ & $\boldsymbol{p}$ \\
\hline Native speaker & 0.150 & 0.103 & 1.452 & 0.148 \\
High & -0.075 & 0.134 & -0.559 & 0.577 \\
Intermediate & -0.429 & 0.116 & -3.685 & $<0.0005^{\text {** }}$ \\
Low & -0.420 & 0.136 & -3.096 & $0.002^{\star *}$ \\
\hline
\end{tabular}

${ }^{\star *}<0.005,{ }^{* \star *}<0.0005$. 
Table 3: Linear regression: Comparison across groups in the canonical suffixal passive construction (acceptability judgment) (alpha level $=0.025$ ).

\begin{tabular}{lrrrr}
\hline Comparison & $\boldsymbol{\beta}$ & $\boldsymbol{S E}$ & $\boldsymbol{t}$ & $\boldsymbol{p}$ \\
\hline Native speaker versus High & -0.121 & 0.105 & -1.152 & 0.251 \\
High versus Intermediate & -0.202 & 0.133 & -1.519 & 0.131 \\
High versus Low & -0.703 & 0.134 & -5.250 & $<0.0005^{\star \star \star}$ \\
Intermediate versus Low & -0.502 & 0.135 & -3.703 & $<0.0005^{\star \star \star}$ \\
\hline
\end{tabular}

$\star \star * * 0.0005$.

\subsubsection{Reaction time}

The global model revealed main effects of Group $(\beta=0.190, S E=0.020, t=9.529$, $p<0.001)$ and Construction $(\beta=0.218, S E=0.083, t=2.632, p=0.019)$ but no interaction effect between these two factors. This indicates that (i) reaction times were modulated by proficiency or construction types and (ii) the changes in reaction times were not affected by the interaction between the two factors.

By-construction comparisons (Table 4) showed that all the groups differed significantly in reaction times across the two constructions: reaction times were uniformly longer for the canonical suffixal passive than for the canonical active transitive. By-group comparisons of reaction times for the canonical suffixal passive (Table 5) did not reveal any statistically significant differences across the learner groups in processing, except for the comparison between the native speaker group and the high-proficiency group. Combined with the tendency found in the numeric values in Table 1, this finding suggests that the learners spent almost the same amount of time in rating the acceptability of the canonical suffixal passive.

Table 4: Linear mixed-effects modelling: Comparison between the canonical active transitive and canonical suffixal passive constructions by group (reaction time) (alpha level $=0.025$ ).

\begin{tabular}{lrrrr}
\hline Group & $\boldsymbol{\beta}$ & $\boldsymbol{S E}$ & $\boldsymbol{t}$ & $\boldsymbol{p}$ \\
\hline Native speaker & 0.260 & 0.065 & 3.983 & $<0.0005^{\star \star *}$ \\
High & 0.177 & 0.069 & 2.548 & $0.012^{*}$ \\
Intermediate & 0.150 & 0.064 & 2.366 & $0.019^{*}$ \\
Low & 0.258 & 0.092 & 2.802 & $0.005^{*}$ \\
\hline
\end{tabular}

*< $0.025 ;{ }^{\star \star \star}<0.0005$. 
Table 5: Linear mixed-effects modelling: Comparison across groups in the canonical suffixal passive construction (reaction time) (alpha level $=0.025$ ).

\begin{tabular}{|c|c|c|c|c|}
\hline Comparison & $\beta$ & $S E$ & $t$ & $p$ \\
\hline Native speaker versus High & 0.462 & 0.082 & 5.652 & $<0.0005^{\star \star \star}$ \\
\hline High versus Intermediate & 0.071 & 0.106 & 0.667 & 0.508 \\
\hline High versus Low & 0.123 & 0.105 & 1.169 & 0.249 \\
\hline Intermediate versus Low & 0.072 & 0.107 & 0.679 & 0.500 \\
\hline
\end{tabular}

$\star \star \star *<0.0005$.

\subsubsection{Interpretation of results}

Regarding the acceptability judgment, we found that learners had lower acceptability rates for the canonical suffixal passive (relative to the canonical active transitive) and their rates improved as their proficiency increased. This finding is consistent with the aforementioned difficulty in acquiring the passive construction, providing judgment evidence for the isomorphic mapping hypothesis. This also suggests that knowledge about the Korean suffixal passive construction is proportionate to proficiency.

Reaction times were longer for the canonical suffixal passive than for the canonical active transitive, and they decreased as proficiency increased. One possible interpretation of these findings is that a construction involving non-isomorphic mapping (the canonical suffixal passive) requires more processing resources than that involving isomorphic mapping (the canonical active transitive). However, it is not clear at this stage whether the longer reaction times in the passive were attributed solely to non-isomorphic mapping, because it is indicated by case-marking and verbal morphology, which are particular to a passive voice and could also generate this difference in reaction times independently of the actual mapping nature.

\subsection{Statistical comparison: canonical active transitive versus scrambled suffixal passive}

Like the canonical active transitive, the scrambled suffixal passive is isomorphic (i.e., agent-before-theme); however, it engages in the unusual case-marking together with passive morphology. Comparing the two construction types enables us to measure the influences of passive-specific case-marking and verbal morphology (with the mapping relation controlled), which was unclear to be assessed in the earlier comparison in performance between the canonical active transitive and the canonical suffixal passive. 


\subsubsection{Acceptability judgment}

In the global model, we found main effects of Group $(\beta=-0.212, S E=0.028$, $t=-7.667, p<0.001)$ and Construction $(\beta=-0.709, S E=0.063, t=-11.235, p<0.001)$ and an interaction effect between these two factors $(\beta=-0.316, S E=0.055, t=-5.719$, $p<0.001)$. The two main effects indicate that acceptability rates were modulated by proficiency and construction types. Considering the tendency found in the numeric values in Table 1, the locus of the interaction effect lies in a bigger change in acceptability rates for the scrambled suffixal passive than for the canonical active transitive as proficiency increased.

By-construction comparisons (Table 6) showed that, except for the native speaker group, the acceptability rates of the two constructions differed significantly for all the learner groups. This suggests that, as already found in Table 1, all the learner groups judged the scrambled suffixal passive to be less acceptable than the canonical active transitive. By-group comparisons within the scrambled suffixal passive (Table 7) showed a significant difference between the native speaker group and the high-proficiency group. Amongst the learner groups, only the highproficiency group demonstrated a significantly better rate of acceptability than the low-proficiency group. However, considering the numeric values ( 2.61 for the highproficiency group; 2.28 for the low-proficiency group), the learner groups' performance is fairly consistent with the earlier finding, pointing to their uniformly low acceptability rates for the scrambled suffixal passive.

\subsubsection{Reaction time}

The global model revealed a main effect of Group $(\beta=0.185, S E=0.020, t=9.203$, $p<0.001$ ), but there was no main effect of Construction and no interaction between these two factors. This indicates that all the learner groups took longer to judge acceptability than the native speaker group, irrespective of the construction types.

Table 6: Linear regression: Comparison between the canonical active transitive and scrambled suffixal passive constructions by group (acceptability judgment) (alpha level $=0.025$ ).

\begin{tabular}{lrrrr}
\hline Group & $\boldsymbol{\beta}$ & $\boldsymbol{S E}$ & $\boldsymbol{t}$ & $\boldsymbol{p}$ \\
\hline Native speaker & -0.033 & 0.106 & -0.316 & 0.752 \\
High & -0.950 & 0.148 & -6.413 & $<0.0005^{\star \star \star}$ \\
Intermediate & -1.125 & 0.121 & -9.269 & $<0.0005^{\star \star \star}$ \\
Low & -0.920 & 0.132 & -6.952 & $<0.0005^{* \star *}$ \\
\hline
\end{tabular}

$\star \star \star<0.0005$. 
Table 7: Linear regression: Comparison across groups in the scrambled suffixal passive construction (acceptability judgment) (alpha level $=0.025$ ).

\begin{tabular}{lrrrr}
\hline Comparison & $\boldsymbol{\beta}$ & $\boldsymbol{S E}$ & $\boldsymbol{t}$ & $\boldsymbol{p}$ \\
\hline Native speaker versus High & -0.813 & 0.120 & -6.784 & $<0.0005^{\star \star \star}$ \\
High versus Intermediate & -0.093 & 0.147 & -0.633 & 0.528 \\
High versus Low & -0.328 & 0.143 & -2.291 & $0.023^{*}$ \\
Intermediate versus Low & -0.235 & 0.135 & -1.748 & 0.082 \\
\hline
\end{tabular}

${ }^{*}<0.025 ;{ }^{* \star *}<0.0005$.

By-construction comparisons (Table 8) yielded no statistically significant differences in all the groups. In other words, participants spent an equal amount of time in rating the two construction types. In contrast, by-group comparisons for the scrambled suffixal passive (Table 9) showed a statistically significant difference only in between the native speaker group and the high-proficiency group. These findings indicate that the learners spent a uniform amount of time judging acceptability and the time that they spent was longer than the time spent by the native speaker group.

Table 8: Linear mixed-effects modelling: Comparison between the canonical active transitive and scrambled suffixal passive construction by group (reaction time) (alpha level $=0.025$ ).

\begin{tabular}{lrrrr}
\hline Group & $\boldsymbol{\beta}$ & $\boldsymbol{S E}$ & $\boldsymbol{t}$ & $\boldsymbol{p}$ \\
\hline Native speaker & 0.086 & 0.087 & 0.996 & 0.334 \\
High & -0.019 & 0.063 & -0.295 & 0.772 \\
Intermediate & 0.006 & 0.081 & 0.075 & 0.941 \\
Low & 0.041 & 0.113 & 0.367 & 0.720 \\
\hline
\end{tabular}

Table 9: Linear mixed-effects modelling: Comparison across groups in the scrambled suffixal passive construction (reaction time) (alpha level $=0.025$ ).

\begin{tabular}{lrrrr}
\hline Comparison & $\boldsymbol{\beta}$ & $\boldsymbol{S E}$ & $\boldsymbol{t}$ & $\boldsymbol{p}$ \\
\hline Native speaker versus High & 0.394 & 0.078 & 5.041 & $<0.0005^{\star \star \star}$ \\
High versus Intermediate & 0.132 & 0.123 & 1.072 & 0.289 \\
High versus Low & 0.108 & 0.119 & 0.913 & 0.366 \\
Intermediate versus Low & -0.021 & 0.128 & -0.162 & 0.872 \\
\hline
\end{tabular}

$\star * \star<0.0005$. 


\subsubsection{Interpretation of results}

In this comparison, we found that the learners judged the scrambled suffixal passive to be less acceptable than the canonical active transitive, despite the fact that both constructions feature isomorphic mapping. We also found that learners' reaction times for the scrambled suffixal passives were the same as their reaction times for the canonical active transitive. These findings bear two interpretations. First, learners may have benefitted from isomorphic mapping in processing the scrambled suffixal passive (as occurred with native speakers), although their processing was slower than the native speakers' processing in general. Second, despite this processing benefit, language-specific devices-case-marking and passive morphology-uniformly decreased the learners' acceptability ratings of this passive construction (relative to the canonical active transitive).

\subsection{Statistical comparison: canonical suffixal passive versus scrambled suffixal passive}

The two passive patterns share unusual case-marking and passive morphology, but they are different with respect to the mapping relation: the canonical suffixal passive is non-isomorphic (i.e., theme-before-agent) whereas the scrambled suffixal passive is isomorphic (i.e., agent-before-theme). This comparison thus allows us to measure the impacts of the mapping relation between the two representations, controlling for the language-specific devices in the passive.

\subsubsection{Acceptability judgment}

In the global model, we found main effects of Group $(\beta=-0.312, S E=0.027$, $t=-11.640, p<0.001)$ and Construction $(\beta=-0.559, S E=0.061, t=-9.136, p<0.001)$ and an interaction effect between these two factors $(\beta=-0.117, S E=0.054, t=2.179$, $p<0.001$ ). This suggests that (i) acceptability rates were contingent upon proficiency (i.e., learners' judgments improved as proficiency increased) and construction types (i.e., the canonical suffixal passive was judged to be more acceptable than the scrambled suffixal passive) and (ii) construction types modulated the degree to which acceptability rates improved by proficiency, as indicated by the interaction effect.

By-construction comparisons (Table 10) showed that all the learner groups differed significantly in their judgments of the two passive patterns. This indicates that the learners rated the scrambled suffixal passive as less acceptable than the canonical suffixal passive. The analysis showed no significant difference for the 
Table 10: Linear regression: Comparison between the canonical and scrambled suffixal passive constructions by group (acceptability judgment) (alpha level $=0.025$ ).

\begin{tabular}{|c|c|c|c|c|}
\hline Group & $\beta$ & $S E$ & $t$ & $p$ \\
\hline Native speaker & -0.183 & 0.087 & -2.109 & 0.036 \\
\hline High & -0.875 & 0.145 & -6.032 & $<0.0005^{\star \star \star}$ \\
\hline Intermediate & -0.798 & 0.130 & -6.148 & $<0.0005^{\star * *}$ \\
\hline Low & -0.500 & 0.133 & -3.768 & $<0.0005^{\star \star \star}$ \\
\hline
\end{tabular}

$\star * *<0.0005$.

native speaker group in this comparison, but participants in this group did prefer the canonical pattern over the scrambled one numerically (as found in Table 1).

\subsubsection{Reaction time}

The global model revealed a main effect of Group $(\beta=0.175, S E=0.020, t=8.631$, $p<0.001)$, a marginal main effect of Construction $(\beta=-0.183, S E=0.096, t=-1.915$, $p=0.074$ ), and no interaction between these two factors. This indicates that reaction times became shorter as proficiency increased, and that participants took longer to judge the canonical suffixal passive than in judging the scrambled suffixal passive (although weak).

By-group comparisons (Table 11) showed significance in all the groups (with a borderline $p$-value for the intermediate-proficiency group). This indicates that participants tended to take longer to judge the acceptability of the canonical suffixal passive than that of the scrambled suffixal passive. In other words, controlling for the language-specific devices (i.e., case-marking and verbal morphology), nonisomorphic mapping incurred greater processing cost than isomorphic mapping.

Table 11: Linear mixed-effects modelling: Comparison between the canonical and scrambled suffixal passive constructions by group (reaction time) (alpha level $=0.025$ ).

\begin{tabular}{lrrrr}
\hline Group & $\boldsymbol{\beta}$ & $\boldsymbol{S E}$ & $\boldsymbol{t}$ & $\boldsymbol{p}$ \\
\hline Native speaker & -0.173 & 0.064 & -2.697 & $0.008^{*}$ \\
High & -0.197 & 0.073 & -2.695 & $0.008^{*}$ \\
Intermediate & -0.146 & 0.065 & -2.261 & 0.025 \\
Low & -0.222 & 0.090 & -2.474 & $0.015^{*}$ \\
\hline
\end{tabular}

*<0.025. 


\subsubsection{Interpretation of results}

This comparison, controlling for the language-specific devices in the passive, showed that the learners rated the canonical suffixal passive as more acceptable (with longer reaction times) than the scrambled counterpart. These findings have two interpretations. First, non-isomorphic mapping, a mapping relation inherent to the passive, involves more processing costs than isomorphic mapping. Second, an additional challenge in acquisition of the passive arises when language-specific devices provide conflicting cues for the mapping relation of the passive, as in the case of the scrambled suffixal passive.

\section{Discussions and conclusion}

The current study investigated L2 comprehension of the suffixal passive construction in Korean by Mandarin-speaking learners of Korean, seeking to address how isomorphism, together with language-specific devices, explains L2 acquisition of the passive. Isomorphism concerns the thematic role ordering as a clause level; language-specific devices concern the local form-function associations of arguments (case-marking) and the activation/confirmation of particular types of associations involving case-marking (verbal morphology). If a comprehender finds passive morphology in a verb, they proceed to realigning the form-function mapping of the nominative case marker and the dative marker; this revision is either consistent (thus isomorphic; scrambled) or inconsistent (thus non-isomorphic; canonical) with the event representation. In this study, we measured learners' acceptability judgment of the canonical and scrambled passives, together with their reaction times. In general, the learners judged the two passive patterns to be less acceptable than the canonical active transitive, and they uniformly preferred the canonical suffixal passive over the corresponding scrambled pattern. As proficiency increased, the learners' judgment gap between the canonical active transitive and the canonical suffixal passive tended to narrow, but we did not find the same tendency for the gap between the canonical active transitive and the scrambled suffixal passive. The learners spent more time in rating the acceptability of the test sentences than the native speakers, regardless of proficiency. In particular, the learners (and even the native speakers) spent more time in judging the acceptability of the canonical suffixal passive than they did in the other two construction types.

Our results clearly support the relevance of the isomorphic mapping hypothesis concerning L2 comprehension of the suffixal passive in Korean. We found that participants spent more time responding to the canonical suffixal passive than the its scrambled counterpart. This suggests that a mismatch in alignment between the 
event and syntactic representations (i.e., non-isomorphic mapping) incurs greater processing cost than a typical alignment between them (i.e., isomorphic mapping). We also found that learners judged the canonical suffixal passive to be less acceptable than the canonical active transitive. This is ascribable to the possibility that the mapping discrepancy in the passive complicates learners' interpretation of that construction, leading them to disprefer the passive over the active. In addition, the learners' acceptability rates for the canonical suffixal passive improved as their proficiency increased, further highlighting the role of proficiency (as a proxy for learning experience) in the successful acquisition of this construction type.

The findings of this study also support the role of language-specific devices indicating the mapping nature of a passive voice in L2 learners' comprehension of Korean suffixal passive. The learners in this study rated the scrambled suffixal passive less acceptable than the canonical active transitive, with a compelling amount of reaction times between the two construction types. Considering that these constructions share isomorphic mapping, one promising source for the lower rating of the scrambled suffixal passive is the combination of the unusual case-marking and verbal morphology inherent to the passive. Learning the new form-function associations of case-marking, in conjunction with the intricacies involving verbal morphology, is indeed an important task for learners seeking to comprehend the suffixal passive in Korean (e.g., Shin 2020; cf. Stromswold et al. 1985), but they do not exist or they behave in different ways in the learners' native language. The fact that even the high-proficiency learners dispreferred the scrambled suffixal passive implies that learning how these language-specific devices contribute jointly to a passive voice is a real challenge for L2 development.

More importantly, our findings shed light on how the mapping relation in the passive is intertwined with language-specific devices unique to this construction in the course of L2 comprehension. Our participants spent more time judging the acceptability of the canonical suffixal passive than the scrambled suffixal passive, but they preferred the canonical suffixal passive over the scrambled counterpart. Across languages, the passive is essentially difficult to learn because its nonisomorphic nature incurs greater processing cost, which makes it less favoured. Despite the costly processing of the canonical suffixal passive in Korean, Mandarinspeaking learners can improve their interpretations of this passive type gradually, because the mapping relation inherent to this passive pattern is also the default composition of the passive in their native language (and in many other languages as well). Under these circumstances, learners can improve their understanding of the canonical suffixal passive in Korean as their proficiency increase such that they deal with cues from case-marking and verbal morphology involving the mapping nature of this particular construction successfully. In other words, there is an obvious processing load involving the canonical suffixal passive, but learners can overcome 
the processing barrier and succeed in comprehending the passive as they accumulate learning experience (i.e., proficiency). ${ }^{9}$

In contrast, the scrambled suffixal passive follows isomorphic mapping, and thus does not incur the same kind of processing cost induced by the mapping relation in the canonical suffixal passive. The insignificant differences in participants' reaction times in judging the acceptability of the scrambled suffixal passive relative to the canonical active transitive supports this possibility. The key observation here is that learners deemed the scrambled suffixal passive unacceptable at a higher rate than its canonical counterpart. The scrambled suffixal passive manifests two conflicting cues simultaneously: case-marking (an initial dative-marked agent argument and a non-initial nominative-marked theme argument, thus yielding the agent-theme ordering) and verbal morphology (signalling that the sentence is in a passive voice and thus non-isomorphic by nature). Moreover, the thematic role ordering of this passive pattern (i.e., agent-before-theme) differs from that of the Mandarin passive. The misalignment between the two cues in the scrambled suffixal passive, which also conflicts with non-isomorphic mapping, may thus have led our learners, across proficiency levels, to accept this pattern at lower rates.

Taken together, our acceptability judgment and reaction time findings highlight an asymmetry in L2 comprehension of Korean suffixal passive by canonicity, which is modulated by (non-)isomorphic mapping of the passive indicated by language-specific devices unique to the passive. To the best of our knowledge, this is the first attempt to relate $\mathrm{L} 2$ comprehension of a passive construction to isomorphism in conjunction with language-specific devices. If our interpretation is on the right track, this line of thinking encourages us to embrace the novel idea that the ability to capture and realign the mapping of event and syntactic representations, together with managing language-specific devices, connects to L2 development. The idea presents robust areas for future research including constructions

9 As one reviewer raised, the learners' performance in the passive patterns might result from instruction effects. Whilst this seems reasonable, there are reasons that we hesitate to argue strongly that instruction effects (not the isomorphic mapping hypothesis) address their comprehension behaviours in this study. First of all, it is difficult to equate the proficiency groups (classified by separate proficiency measurement) with the relative length that each group was exposed to instruction. We reported the mean years of learning Korean by proficiency (Table A1 in Appendix A), but this does not entail, for example, that the low-proficiency group did not take any intermediate- or advanced-level Korean courses (which are assumed to introduce complex constructions such as the passives). Moreover, because the participants lived in Korea when we conducted the experiment, it is possible that they had been exposed to passive voice instances in real life, which we cannot control. Precisely addressing instruction effects on L2 comprehension/ processing of the suffixal passive in Korean is out of scope here, which requires additional research on intervention of target language knowledge and comparisons of pre- and post-tests for learner performance. 
with various (non-)isomorphic mapping relations, combined with characteristics of the target language (e.g., scrambling and omission of sentential components in Korean), in consideration of task environment (cf. McDonald 2006) or L2 learners' memory capacities (cf. Hopp 2014).

Note that the suffixal passive construction in Korean involves atypical casemarking that indicates the thematic roles of arguments (i.e., a nominative case marker for the theme and a dative marker for the agent) and verbal morphology that indicates these unusual case-marking to signal the mapping nature of the passive. The fact that the learners in the current study gradually improved their judgments of the passive (although in a manner asymmetrically contingent upon canonicity) may then be understood as reflecting their increased sensitivity to (or enhanced knowledge of) the language-specific devices unique to the passive. Indeed, participants were asked to respond to the given task without any context for each test sentence. ${ }^{10}$ In this zero-context acceptability judgment setting, they might have focused exclusively on structural cues such as case-marking and passive morphology. Our findings thus stand as an indication that acquiring new form-function pairings of markers in conjunction with verbal morphology may be correlated to the success in comprehending the passive, assisting L2 learners in accommodating the mapping between event and syntactic representations engaging in the passive.

Acknowledgements: This study was supported by the European Regional Development Fund through the 'Sinophone Borderlands - Interaction at the Edges’ project (CZ.02.1.01/0.0/0.0/16_019/0000791).

\section{Appendix A Information about the experiment}

Table A1: Participant information.

\begin{tabular}{lrrrr}
\hline Group & Number & $\begin{array}{r}\text { Mean years of learning } \\
\text { Korean (SD) }\end{array}$ & $\begin{array}{r}\text { Mean years of staying } \\
\text { Korea (SD) }\end{array}$ & $\begin{array}{r}\text { Mean score of } \\
\text { TOPIK (SD) }\end{array}$ \\
\hline High & 20 & $4.29(5.31)$ & $2.14(1.76)$ & $26.00(1.81)$ \\
Intermediate & 26 & $3.00(2.34)$ & $1.68(1.04)$ & $16.73(2.01)$ \\
Low & 22 & $2.30(1.47)$ & $1.45(1.14)$ & $10.14(2.01)$ \\
\hline
\end{tabular}

10 This kind of experimental setting may increase L2 learners' overall processing loads. Future studies would benefit from considering providing participants contextual information relevant to judging the acceptability of test sentences. 
Table A2: ANOVA table.

\begin{tabular}{lrrrrrr}
\hline Source & SS & $\boldsymbol{d f}$ & MS & $\boldsymbol{F}$ & $\boldsymbol{p}$ & $\boldsymbol{\eta}^{\mathbf{2}}$ \\
\hline Proficiency & $2,651.176$ & 2 & $1,325.588$ & 347.844 & $<0.001^{\star \star \star}$ & 0.915 \\
Error & 247.706 & 65 & 3.811 & & & \\
Total (corrected) & $2,898.882$ & 67 & & & & \\
\hline
\end{tabular}

$\star * \star<0.001$.

Table A3: Post-hoc analysis: Pairwise comparison (Tukey HSD).

\begin{tabular}{llrrr}
\hline Proficiency: base & Proficiency: comparison & Mean difference & SD & $p$ \\
\hline High & Intermediate & 9.27 & 0.58 & $<0.001^{\star \star \star}$ \\
Intermediate & Low & 15.86 & 0.60 & $<0.001^{\star \star \star}$ \\
\hline
\end{tabular}

$\star \star \star<0.001$.

\section{Appendix B Test sentences: active transitives \& suffixal passives}

$<$ Active transitive construction $>$

Unse-ka Hyencwu-lul manna-ss-eyo.

Unse-NOM Hyencwu-ACC meet-PST-SE

'Unse met Hyencwu.'

Sungcay-ka Yengswu-lul mit-ess-eyo.

Sungcay-NOM Yengswu-ACC trust-PST-SE

'Sungcay trusted Yengswu.'

Cina-ka Unmi-lul cap-ass-eyo.

Cina-NOM Unmi-ACC catch-PST-SE

'Cina caught Unmi.'

Siwu-ka Myengswu-lul chilha-yss-eyo.

Siwu-NOM Myengswu-ACC paint-PST-SE

'Siwu painted Myengswu.'

Pola-ka Hyeyci-lul iky-ess-eyo.

Pola-NOM Hyeyci-ACC defeat-PST-SE

'Pola defeated Hyeyci.' 
Sungha-ka Cengho-lul ppop-ass-eyo.

Sungha-NOM Cengho-ACC pick-PST-SE

'Sungha picked Cengho.'

Cia-ka Yeyci-lul talm-ass-eyo.

Cia-NOM Yeyci-ACC resemble-PST-SE

'Cia resembled Yeyci.'

Tongkyu-ka Kencwu-lul kitaly-ess-eyo.

Tongkyu-NOM Kencwu-ACC wait-PST-SE

'Tongkyu waited for Kencwu.'

$<$ Suffixal passive construction>

Cwunho-ka Sungwu-hanthey cha-i-ess-eyo.

Cwunho-NOM Sungwu-DAT kick-PSV-PST-SE

'Cwunho was kicked by Sungwu.'

Mina-ka Yengmi-hanthey mil-li-ess-eyo.

Mina-NOM Yengmi-DAT push-PSV-PST-SE

'Mina was pushed by Yengmi.'

Cwunse-ka Namkyu-hanthey cap-hi-ess-eyo.

Cwunse-NOM Namkyu-DAT catch-PSV-PST-SE

'Cwunse was caught by Namkyu.'

Minha-ka Cayhuy-hanthey mwul-li-ess-eyo.

Minha-NOM Cayhuy-DAT bite-PSV-PST-SE

'Minha was bitten by Cayhuy.'

Yengho-ka Congswu-hanthey an-ki-ess-eyo.

Yengho-NOM Congswu-DAT hug-PSV-PST-SE

'Yengho was hugged by Congswu.'

Yumi-ka Uncwu-hanthey palp-hi-ess-eyo.

Yumi-NOM Uncwu-DAT trample-PSV-PST-SE

'Yumi was trampled by Uncwu.'

Sekcwu-ka Hyenwu-hanthey ep-hi-ess-eyo.

Sekcwu-NOM Hyenwu-DAT piggyback-PSV-PST-SE

'Sekcwu was piggybacked by Hyenwu.' 


\author{
Minse-ka Ciwu-hanthey kkocip-hi-ess-eyo. \\ Minse-NOM Ciwu-DAT pinch-PSV-PST-SE \\ 'Minse was pinched by Ciwu.
}

\title{
References
}

Abbot-Smith, Kirsten, Franklin Chang, Caroline Rowland, Heather Ferguson \& Julian Pine. 2017. Do two and three year old children use an incremental first-NP-as-agent bias to process active transitive and passive sentences?: A permutation analysis. PLoS One 12(10). e0186129.

Balcom, Patricia. 1997. Why is this happened? Passive morphology and unaccusativity. Second Language Research 13(1). 1-9.

Bates, Douglas, Martin Maechler, Ben Bolker \& Steve Walker. 2015. Fitting linear mixed-effects models using Ime4. Journal of Statistical Software 67(1). 1-48.

Barr, Dale J., Roger Levy, Christoph Scheepers \& Harry J. Tily. 2013. Random effects structure for confirmatory hypo testing: Keep it maximal. Journal of Memory and Language 68(3). 255278.

Borer, Hagit \& Kenneth Wexler. 1987. The maturation of syntax. In Thomas Roeper \& A. Edwin Williams (eds.), Parameter Setting, 123-172. Dordrecht: Reidel.

Brooks, Patricia J. \& Michael Tomasello. 1999. Young children learn to produce passives with nonce verbs. Developmental Psychology 35. 29-44.

Choo, Miho \& Hye-Young Kwak. 2008. Using Korean. Cambridge: Cambridge University Press.

Clahsen, Harald \& Claudia Felser. 2006. Continuity and shallow structures in language processing. Applied Psycholinguistics 27. 107-126.

Dąbrowska, Ewa. 2010. Naive v. expert intuitions: An empirical study of acceptability judgments. The Linguistic Review 27(1). 1-23.

de Villiers, Jill G. \& Peter A. de Villiers. 1973. Development of the use of word order in comprehension. Journal of Psycholinguistic Research 2(4). 331-341.

Dik, Simon C. 1997. The theory of functional grammar: The structure of the clause. Berlin: Walter de Gruyter.

Dryer, Matthew S. 2013. Order of subject, object and verb. In Matthew S. Dryer \& Martin Haspelmath (eds.), The world atlas of language structures online. Leipzig: Max Planck Institute for Evolutionary Anthropology Available at: http://wals.info/chapter/81 on 17-Mar2018.

Enochson, Kelly \& Jennifer Culbertson. 2015. Collecting psycholinguistic response time data using Amazon Mechanical Turk. PLoS One 10(3). e0116946.

Fisher, Cynthia. 2002. Structural limits on verb mapping: The role of abstract structure in 2.5-yearolds' interpretations of novel verbs. Developmental Science 5. 55-64.

Fox, Danny \& Yosef Grodzinsky. 1998. Children's passive: A view from the by-phrase. Linguistic Inquiry 29(2). 311-332.

Goldin-Meadow, Susan, Wing Chee So, Aslı Özyürek \& Carolyn Mylander. 2008. The natural order of events: How speakers of different languages represent events nonverbally. In Rochel Gelman (ed.), Proceedings of the National Academy of Sciences, vol. 105, 9163-9168. Haspelmath, Martin. 1990. The grammaticization of passive morphology. Studies in Language 14(1). 25-72. 
Hee, Park Sun \& Kim Hyunwoo. 2017. Second language acquisition and processing of the Korean locative constructions by Chinese speakers. Acta Koreana 20. 591-614.

Hinkel, Eli. 2004. Tense, aspect and the passive voice in L1 and L2 academic texts. Language Teaching Research 8(1). 5-29.

Hopp, Holger. 2014. Working memory effects in the L2 processing of ambiguous relative clauses. Language Acquisition 21(3). 250-278.

Huang, Yi Ting, Xiaobei Zheng, Xiangzhi Meng \& Jesse Snedeker. 2013. Children's assignment of grammatical roles in the online processing of Mandarin passive sentences. Journal of Memory and Language 69(4). 589-606.

Ito, Akihiro. 2007. The interpretation of Japanese word order patterns by adult English-speaking learners of Japanese as a second language. Applied Linguistics 28(3). 466-473.

Izumi, Shinichi \& Usha Lakshmanan. 1998. Learnability, negative evidence and the L2 acquisition of the English passive. Second Language Research 14(1). 62-101.

Jackendoff, Ray \& Ewa Wittenberg. 2014. What you can say without syntax: A hierarchy of grammatical complexity. In Frederick Newmeyer \& Laurel Preston (eds.), Measuring linguistic complexity, 65-82. Oxford University Press.

Jeong, Hae Gwon. 2014. Processing and acquisition of Korean passive voice by Chinese L2 learners. hankwuke kyoyuk [Korean Education] 25(2). 165-186.

Jeong, J. 2017. A study on the L2 Korean acquisition of tense, aspect, and modality pre-final endings by $L 1$ Chinese learners. Seoul, South Korea: Ewha Womans University Unpublished doctoral dissertation.

Jiang, Nan, Eugenia Novokshanova, Kyoko Masuda \& Xin Wang. 2011. Morphological congruency and the acquisition of 12 morphemes. Language Learning 61(3). 940-967.

Ju, Min Kyong. 2000. Overpassivization errors by second language learners: The effect of conceptualizable agents in discourse. Studies in Second Language Acquisition 22(1). 85-111.

Langacker, Ronald W. 1991. Concept, image and symbol: The cognitive basis of grammar. Berlin: Mouton de Gruyter.

Lardiere, Donna. 2009. Some thoughts on the contrastive analysis of features in second language acquisition. Second Language Research 25(2). 173-227.

Lee, Kwee-Ock \& Youngjoo Lee. 2008. An event-structural account of passive acquisition in Korean. Language and Speech, 51(1/2), 133-149.

Li, Charles \& Sandra Thompson. 1981. Mandarin Chinese: A functional reference grammar. Berkeley, CA: University of California Press.

Liu, Na. 2016. The structures of Chinese long and short bei passives revisited. Language and Linguistics 17(6). 857-889.

MacWhinney, Brian. 1997. Second language acquisition and the competition model. In Annette M. B. de Groot \& Judith F. Kroll (eds.), Tutorials in bilingualism: Psycholinguistic perspectives, 113-142. London: Psychology Press.

McDonald, Janet L. 2006. Beyond the critical period: Processing-based explanations for poor grammaticality judgment performance by late second language learners. Journal of Memory and Language 55(3). 381-401.

McEnery, Anthony, Zhonghua Xiao \& Lili Mo. 2003. Aspect marking in English and Chinese: Using the Lancaster Corpus of Mandarin Chinese for contrastive language study. Literary and Linguistic Computing 18. 361-378.

Nguyen, Emma \& William Snyder. 2017. The (non)-effects of pragmatics on children's passives. In Maria LaMendola \& Jennifer Scott (eds.), Proceedings of the 41st Annual Boston University Conference on Language Development, 522-531. Somerville, MA: Cascadilla Press. 
0'Grady, William \& Miseon Lee. 2005. A mapping theory of agrammatic comprehension deficits. Brain and Language 92(1). 91-100.

0’Grady, William, Yoshie Yamashita \& Sun-Young Lee. 2005. A note on canonical word order. Applied Linguistics 26(3). 453-458.

Omaki, Akira \& Barbara Schulz. 2011. Filler-gap dependencies and island constraints in secondlanguage sentence processing. Studies in Second Language Acquisition 33. 563-588.

Pozzan, Lucia \& John C. Trueswell. 2015. Revise and resubmit: How real-time parsing limitations influence grammar acquisition. Cognitive Psychology 80. 73-108.

$\mathrm{R}$ Core Team. 2019. R: A language and environment for statistical computing. Vienna, Austria: $\mathrm{R}$ Foundation for Statistical Computing.

Ratcliff, Roger. 1993. Methods for dealing with reaction time outliers. Psychological Bulletin 114. 510-532.

Sano, Tetsuya, Mika Endo \& Kyoko Yamakoshi. 2001. Developmental issues in the acquisition of Japanese unaccusatives and passives. In Anna H.-J. Do, Laura Domínguez \& Aimee Johansen (eds.), Proceedings of the 25th Boston University Conference on Language Development, 668-683.

Siewierska, Anna. 2013. Passive constructions. In Martin Haspelmath, Matthew Dryer, David Gil \& Bernard Comrie (eds.), The world atlas of language structures online. Leipzig: Max Planck Institute for Evolutionary Anthropology. Available at: http://wals.info/chapter/107 on 10JUL-2020.

Shibatani, Masayoshi. 1985. Passives and related constructions: A prototype analysis. Language 61(4). 821-848.

Shin, Gyu-Ho. 2020. Connecting input to comprehension: First language acquisition of active transitives and suffixal passives by Korean-speaking preschool children. University of Hawai'i at Mānoa Unpublished doctoral dissertation.

Shin, Gyu-Ho \& Boo Kyung Jung. 2021. Automatic analysis of learner corpora in Korean: Written production of Korean passive constructions for Mandarin-speaking learners of Korean. International Journal of Learner Corpus Research 7(1). 53-82.

Slabakova, Roumyana. 2014. The bottleneck of second language acquisition. Foreign Language Teaching and Research 46(4). 543-559.

Slobin, Dan I. \& Thomas G. Bever. 1982. Children use canonical sentence schemas: A crosslinguistic study of word order and inflections. Cognition 12(3). 229-265.

Stromswold, Karin, Steven Pinker \& Ronald Kaplan. 1985. Cues for understanding the passive voice. Papers and Reports on Child Language Development 24. 123-130.

Sohn, Ho-Min. 1999. The Korean language. Cambridge University Press.

Song, Jae Jung. 2015. Causatives. In Lucien Brown \& Jaehoon Yeon (eds.), The handbook of Korean linguistics, 116-136. Oxford: John Wiley \& Sons.

Sun, Chao-Fen \& Talmy Givon. 1985. On the so-called SOV word order in Mandarin Chinese: A quantified text study and its implications. Language 61. 329-351.

Talmy, Leonard. 1988. Force dynamics in language and cognition. Cognitive Science 12(1). 49-100. Xiao, Richard, Tony McEnery \& Yufang Qian. 2006. Passive constructions in English and Chinese: A corpus-based contrastive study. Languages in Contrast 6(1). 109-149.

Yeon, Jaehoon. 2015. Passives. In Lucien Brown \& Jaehoon Yeon (eds.), The handbook of Korean linguistics, 116-136. Oxford: John Wiley \& Sons. 